UCRL-JC- -103815

DE91 000945

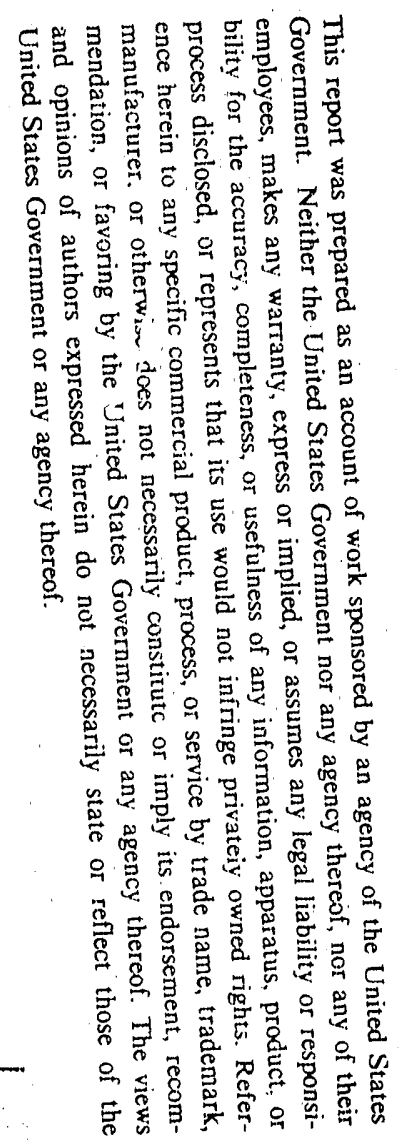

Parametric Cost Analysis of a HYLIFE-II Power Plant

量
Robert L. Bieri

This paper was prepared-for submittal to the 9th Topical Meeting

on the Technology of Fusion Energy October 7-11, 1990

\title{
October 4,1990
}

This is a preprint of a paper intended for publication in a journal or procredings. Since changes may be made before publication, this preprint is made available with the understanding that it will not be cited or reproduced without the permission of the author. 


\title{
Parametric Cost Analysis of a HYLIFE-II Power Plant
}

\author{
Robert L. Bieri \\ LLNL/MIT
}

Abstract:

The SAFIRE (Systems Analysis for ICF Reactor Economics) code was adapted to model a power plant using a HYLIFE-II reactor chamber. The code was then used to examine the dependence of the plant capital costs and busbar cost of electricity (COE) on a variety of design parameters (type of driver, chamber repetition rate, and net electric power). The results show the most attractive operating space for each set of driver/target assurnptions and quantify the benefits of improvements in key design parameters. The base case plant was a 1,000 MWe plant containting a reactor vessel driven by an induction linac heavy ion accelerater run at $7.3 \mathrm{~Hz}$ with a driver energy of $5 \mathrm{MJ}$ and a target yield of $370 \mathrm{MJ}$. The total direct cost for this plant was $2,800 \mathrm{M} \$$ (where all $\$$ in this paper are $1988 \$ \mathrm{~s}$ ), and the COE was 9 $\phi / \mathrm{kW}^{*}$ hour. The COE and total capital costs for the base plant assumptions for a 1,000 MWe plant are approximately independent of chosen repetition rate for all repetition rates between 4 and $10 \mathrm{~Hz}$. For comparison, the COE for a coal or future fission plant would be $4.5-5.5 \phi / \mathrm{KW}^{*}$ hour. The $\mathrm{COE}$ for a $1,000 \mathrm{MWe}$ plant could be reduced to $7.6 \phi / \mathrm{KW}^{*}$ hour by using advanced targets and could be cut to 6.8 $\phi / \mathrm{KW}^{*}$ hour with conventional targets if the driver cost could be cut in half. There is a large economy of scale with heavy ion driven ICF plants; a 5,000 MWe plant with one heavy ion driver and either one or two HYLIFE-II chambers would have a $\mathrm{COE}$ of only $4.4 \phi / \mathrm{KW}$ *hour.

The SAFIRE Code:

The SAFIRE code[1] evolved from a code developed by TRW and LLNL in 1979 to evaluate the performance of fusion-fission hybrids. The code was updated and modified to model Inertial Confinement Fusion (ICF) power plants. In its present form, it allows for either $\mathrm{KrF}$ laser drivers or heavy ion (HI) indution linac drivers. It also models several ICF reactor chambers, but for this study only the HYLIFE-II chamber modeling was used. The balance of plant (BOP) costs are normalized to nuclear industry data from the Energy Economic Data Base [2,3] or the Nuclear Eisergy Cost Data Base.[4] The model for the HI induction linac is based on work done at LBL with the LIACEP code[5], and the KrF model is based on work at Los Alamos [6,7,8,]. 
Economic Assumptions in SAFIRE constant dollar analysis[9]:

Inflation factors:

Since components are costed relative to a variety of reference years, the costs must all be adjusted to 1988 \$s. The adusted cost is given by:

$\mathrm{C}(1988 \$)=\mathrm{C}(\mathrm{r} \$)\left(1+\mathrm{i}_{\mathrm{r}}\right)\left(1+\mathrm{i}_{\mathrm{r}+1}\right) \ldots\left(1+\mathrm{i}_{1988}\right)$,

where

$\mathrm{C}=$ component cost,

$\mathbf{r}=$ reference year,

$\mathrm{i}=$ annual inflation factor.

The total direct cost (TDC) is then the sum all the component costs.

Total Overnite Costs:

The total overnite costs includes indirect costs which are taken to be a fixed fraction of the TDC, except for the contingency cost which is assumed proportional to the sum of the direct and indirect costs. The resulting total overnight cost (TOC) is:

$\mathrm{TOC}=(1+\mathrm{f} 5)(1+\mathrm{f} 1+\mathrm{f} 2+\mathrm{f} 3+\mathrm{f} 4) \mathrm{TDC}$,

where,

$\mathrm{f} 1=0.2=$ fraction for construcion services and equipment,

$\mathrm{f} 2=0.15=$ fraction for home office engineering and service,

$\mathrm{f} 3=0.1=$ fraction for field office engineering and service,

$\mathrm{f} 4=0.07=$ fraction for owner's cost, and $\mathrm{f} 5=$ fraction for plant contingency.

Time Related Costs:

Time related costs include cost escalation during construction and interest during construction. Since the cost escalation rate is assumed equal to the general inflation rate, there are no escalation costs in a constant dollar analysis. The total interest costs, $T_{I D C}$ are given by $T_{I D C}=f_{I D C} *$ TOC where:

FIDC $=(1.028)^{0.4 t-1}$

for

$1.028=1+$ the fractional real cost of money, and $\mathrm{t}=8$ years $=$ the duration of the construction period. 
The COE:

The COE is then calculated as:

$$
\mathrm{COE}=\frac{\mathrm{R}(\mathrm{TCC})+\mathrm{M}+\mathrm{F}}{0.0876 \mathrm{P}_{\mathrm{n}} \mathrm{a}} \quad(\phi / \mathrm{KW} \text { *hour })
$$

where,

$\mathrm{R}=$ the annual fixed charge rate on capital $(1 / \mathrm{yr})$,

TCC $=$ the total capital cost of the plant $(\$ M)$,

$\mathrm{M}=$ the annual operation and maintenance cost $(\$ M)$,

$\mathrm{F}=$ the annual fuel cycle cost $(\$ \mathrm{M})$

$P_{n}=$ the net electric power of the plant (MWe)

and $\mathrm{a}=0.7=$ the plant availablity fraction.

Scaling of the HYLIFE-II Reactor Chamber:

HYLIFE-II[10] uses a flowing liquid wall similar to that used in HYI.IFE-I, but uses molten Flibe at $650 \mathrm{C}$ instead of molten $\mathrm{Li}$ at $500 \mathrm{C}$, so the HYLIFE-I chamber modeling in SAFIRE had to be changed in several respects:

- The required chamber dimensions had to be scaled from a simplified fluid/gas dynamic model for stresses due to impact of the liquid on the chamber wall.

- The required thickness for the flowing liquid blanket had to be determined from neutron attenuation calculations for Flibe.

- Pump and intermediate heat exchanger (IHX) performance and cost had to be modeled for Flibe. The Flibe IHX's models were developed by Prof. M.

Hoffman at U.C. Davis.

The HYLIFE-II modeling has not all been reviewed and may be refined as the study progresses.

Description of Power Plants Considered:

The base case for a HYLIFE-II 1,000 MW electric power plant assumes a heavy ion beam driver with two-sided illumination of an indirect drive target. The induction linac consists of 16 beams which are split and bent so that half of the beams arrive at each side of the reactor chamber. This case is labelled "Base" in Table IV. 
Another possible case would also use a heavy-ion driver but would use advanced targets so that higher gains can be achieved for a given driver energy. This case is labelled "AT" in Table IV.

One way of lowering the cost of electricity is to use one driver to drive multiple reactor chambers. A representative plant using 2 reactor chambers and a heavy ion beam driver to produce 5,000 MW net electric power is shown in Table IV as the case labelled "5GW/2."

The driver cost generally makes up half of the cost of an ICF power plant. Any cost reduction in the driver leads to significant reductions in the COE. A sample plant where all the SAFIRE generated driver costs were reduced by a factor of 2 is shown in the case, "1/2DC" in Table IV. Because of the large number of variable driver parameters, SAFIRE does not completely optimize the heavy ion driver, and drivers with different combinations of ion energy, ion mass, ion charge state, number of beams in various parts of the linac, etc. could be less expensive. Driver cost improvements may be possible with recirculating linacs or other advanced drives concepts.

Although the illumination geometry required for laser driven targets is much more difficult to accomodate with a HYLIFE-II reactor chamber, it is possible that a HYLIFE-II reactor could be used with a $\mathrm{Kr}$ laser driver. The dielectric turning mirror for a laser driver would have to $b$ : protected from neutrons, $x$-rays, "nd debris with gas jets, mechanical shutters[1], and grazing incidence metal mirrors[12]. A representative plant with a $\mathrm{KrF}$ driver is shown as case "KrF" in Table IV. Because a flowing blanket geometry does not easily allow uniform illumination geometries, a conservative gain curve was used for this case.

Results and Conclusions:

Tables I - III give detailed plant parameters and cost breakdowns for a base case 1,000 MW HYLIFE-II plant used with a 5MJ driver. Some critical assumptions that should be considered when comparing this analysis to others are: the plant availability factor $(0.7)$, the driver efficiency $(0.35)$, and the thermal cycle efficiency (.37). Different assumptions for any of these factors can give significantly different COEs (for instance an assumed plant availability of 0.85 would give an $18 \%$ reduction in the COE). The curves in figure 1 show how some of the key features of the base case plant depend on the chosen chamber repetition rate. One benefit of using heavy ion drivers is that the COE and total capital costs are nearly independent of the driver and chamber repetition rates from 4 to $10 \mathrm{~Hz}$. There is therefore a wide range of combinations of driver energy, chamber yield, and chamber repetition rates which give roughly the same COE and rotal costs if a chamber can be operated above $4 \mathrm{~Hz}$. 
Although our base case plant would have a higher COE than either a coal based or future fission plant, the difference is about a factor of two. A HYLIFE-II based fusion plant could be made economically competitive with future coal or fission plants by using economies of scale with present assumptions on driver and target cost and performance. An example of such a plant would produce 5,000 MW of electric power with a single heavy ion linac driving either one or two reactor chambers operating at $10 \mathrm{~Hz}$. For a 1,000 MW electric plant to be economically competitive, advanced target performance would have to be improved over present assumptions and/or driver cost would have to drop by more than a factor of 2 .

Acknowledgements:

This author would like to thank everyone in the HYLIFE-II group for their comments. Those who's time and help were invaluable include: Ralph Moir, Mike Tobin, Charles Orth, and John Pitts at LLNL, Mike Hoffman at UC-Davis, Roger Bangerter at LBL, and Wayne Meier at W.J.Shafer and Assoc. The author would also like to thank Dan Cohn and the Plasma Fusion Center at MIT for supporting his graduate work at LLNL and LBL. This work was carried out under the auspices of the US Department of Energy by Lawrence Livermore National Laboratory under Contract W-7405-Eng-48.

References:

1) T.J. McCarville, W.R.Meier,C.F. Carson, and B.B. Glasgow, SAFIRE - A System Analysis Code for ICF Reactor Economics, Lawrence Livermore National Laboratory, Livermore, CA, UCRL-15872 Vol. 1

2) Energy Economic Data Base (EEDB) Technical Reference Book, U.S. Department of Energy Report DOE/NE-0059 (Sept. 1984).

3) EEDB Phase VI Update Report, U.S. Department of Energy Report DOE/NE-0051/1 (Sept. 1984).

4) J.G. Delene, G.R. Smolen, H.I. Bowers, and M.L. Myers, Nuclear Energy Cost Data Base -. A Reference Data Base for Nuclear and Coal-fired Powerplant Power Generator Cost Analysis, U.S. Department of Energy Report DOE/NE-0044/2 (March 1984).

5) W.R. Meier, "A New Heavy-Ion Beam Driver Model for the SAFIRE Code," Lawrence Livermore Laboratory report UCRL-15872, Vol, 2, Sup. 1 (March 1987)

6) D.B. Harris and J.H. Pendergrass, "Megajoule - Class Single-Pulse KrF Laser Facility as a Logical Step Toward Inertial Fusion Commercialization," Fusion Technology 8, 1868-1871 (1985) 
7) D.B. Harris and J.H. Pendergrass, "Design Optimization of Single-Main Amplifier KrF Laser-Fusion Systems," Fusion Technology 8, 1872 (1985).

8) D.B. Harris and J.H. Pendergrass, "KrF Laser Cost/Performance Model for ICF Commercial Applications," Fusion Technology 8, 1220 (1985)

9) W.R. Meier, "A Standard Method for Economic Analyses of Inertial Confinement Fusion Power Plants," Fusion Technology 10, 1557 (1986).

10) R.W. Moir, "HYLIFE-II Inertial Confinement Fusion Reactor Design", submitted to these proceedings, LLNL preprint UCRL-JC-103816 (1990).

11) D.G. Nilson ard J.G.Woodworth, "Final Optic Protection Designs for ICF Containment Chambers", LLNL publication.

12) R.L. Bieri and M.W. Giunan, "Grazing Incidence Metal Mirrors as the Final Elements in a Laser Driver for Inertial Confinement Fusion", submitted to these proceedings, LLNL preprint UCRL-JC-103817. 
Table I

Base Case Power Plant Parameters

Plant Parameters:

Chamber Pulse Rate:

$7.3 \mathrm{~Hz}$

Driver Energy:

$5.0 \mathrm{MJ}$

Target Gain:

73.7

Target Yield:

369 MJ

Thermal Power:

3,050 MW

Thermal Cycle Efficiency:

$36.7 \%$

Heat Rejected:

Availability Factor:

$1,930 \mathrm{MW}$

$70 \%$.

Power Balance:

Gross Electric Power:

$1120 \mathrm{MWe}$

Driver Power:

$103 \mathrm{MWe}$

Pumping Power:

15 MWe

Net Electric Power:

1002 MWe

Heavy Ion Driver Parameters:

Driver Beam Energy:

$5.00 \mathrm{MJ}$

Driver Efficiency:

$35.3 \%$

Driver Input Energy/Shot:

$14.07 \mathrm{MJ}$

Driver Repetition Rate:

$7.3 \mathrm{~Hz}$

Recirculating Driver Power: 102.7 MWe

Accelerator length:

$1.36 \mathrm{~km}$

Number of Beams in Accel.:

16

HYLIFE-II Chamber Parameters:

Chamber Radius:

$3.1 \mathrm{~m}$

Chamber Height:

$5 \mathrm{~m}$

Equivalent FSW Thickness:

$27.6 \mathrm{~mm}$

Flibe Blanket Parameters:

Flibe Injection Velocity:

$13.9 \mathrm{~m} / \mathrm{s}$

Pumping Head:

$15 \mathrm{~m}$

Inner Jet Radius:

$0.3 \cdot \mathrm{m}$

Jet Array Eff. Thickness:

$0.53 \mathrm{~m}$

Chamber Flow:

$28.7 \mathrm{~m}^{3} / \mathrm{s}$ 
Reflector Flow:

Flibe Vol. in Chamber:

Pumping Power:
$2.5 \mathrm{~m}^{3} / \mathrm{s}$

$3.9 \mathrm{~m}^{3} / \mathrm{s}$

$15.1 \mathrm{MWe}$ 
Table II

Direct Cost Summaries for The Base Driver and Reactor

Driver Direct Cost Summary(1988 \$s):

Ion Source/Preaccelerator: $\quad 177 \mathrm{M} \$$

Accel Modules and Power Sup.: 979 M\$

Beam Transport System: $\quad 65 \mathrm{M} \$$

Final Focus System: $105 \mathrm{M} \$$

Cooling System: $12 \mathrm{M} \$$

Accel. and Transport Vacuum: $6 \mathrm{M} \$$

Driver Maintenance Equip.: $6 \mathrm{M} \$$

Instrumentation and Control: $\quad 25 \mathrm{M} \$$

Total Driver Direct Cost: 1,396 M\$

Reactor Plant Direct Cost Summary' (1988 \$s):

Tracking,Alignment System: $\quad 30.4 \mathrm{M} \$$

First Wall Systems: $\quad 0.7 \mathrm{M} \$$

T Extraction Systems: $\quad 27.3 \mathrm{M} \$$

Blanket and Shield: $\quad 32.5 \mathrm{M} \$$

Heat Transport System: $\quad 440.9 \mathrm{M} \$$

Total Reactor Plant Costs: $\quad 531.7 \mathrm{M} \$$ 
Table III

Total Capital Costs and COE for the Base Plant

Summary of All Power Plant Capital Costs(1988\$):

$\begin{array}{lr}\text { Account Title } & \mathrm{M} \$ \\ \text { Land and Land Rights } & 5.0 \\ \text { Structures and Improvements } & 278.6 \\ \text { Reactor Plant Equipment } & 531.7 \\ \text { Turbine Plant Equipment } & 226.3 \\ \text { Electric Plant Equipment } & 90.1 \\ \text { Miscellaneous Plant Equipment } & 59.1 \\ \text { Main Heat Rejection Equipment } & 40.4 \\ \text { Driver Equipment } & 1,396.2 \\ \text { Target Factory Equipment } & 127.7 \\ \text { Total Direct Costs: } & 2,755.2 \\ & 551.0 \\ \text { Construction Services } & 413.3 \\ \text { Home Office Eng. and Services } & 275.5 \\ \text { Field Office Eng. and Services } & 192.9 \\ \text { Owner's Cost } & 418.8 \\ \text { Project Contingency } & 4,606.6 \\ \text { Total Overnight Costs } & \\ & 430.3 \\ \text { Interest During Construction } & 5,037.0 \\ \text { Total Capital Cost } & \\ & \\ \text { Of Electricity (in 1988 } \$ \text { s): } & \\ & 6.82 \\ \text { Capital Contribution } & 0.01 \\ \text { Fuel Contribution } & 2.25 \\ \text { Operation \& Maintenance } & 9.08 \\ \text { Total COE } & \end{array}$


Figure Captions:

Figure 1a: $\operatorname{COE}(1988 \$ s)$ vs. Repetition Rate for a 1,000 MW electric plant.

Figure 1b: Reactor and Driver Direct Costs(1988\$s) vs. Repetition Rate for a 1,000 MW electric plant

Figure 1c: Required Driver Energy vs. Repetition Rate for a 1,000 MW electric plant Figure 1d: Target Yield vs. Repetition Rate for a 1,000 MW electric power plant.

Figure 1e: Required Recirculating Power vs. Repetition Rate for a 1,000 MW electric plant

Figure 1f: Assumed Gain Curve for a Heavy Ion Driver 


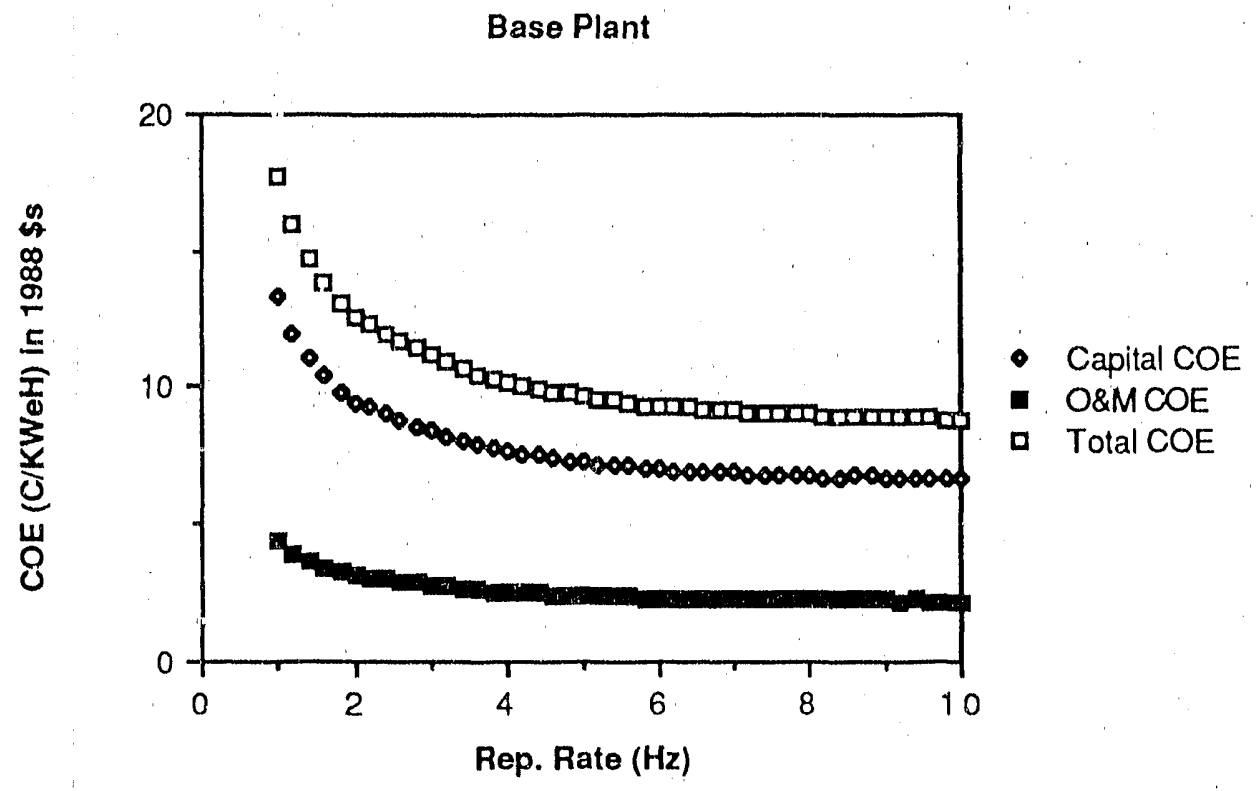

$f \cdot 1 \cdot 19$ 


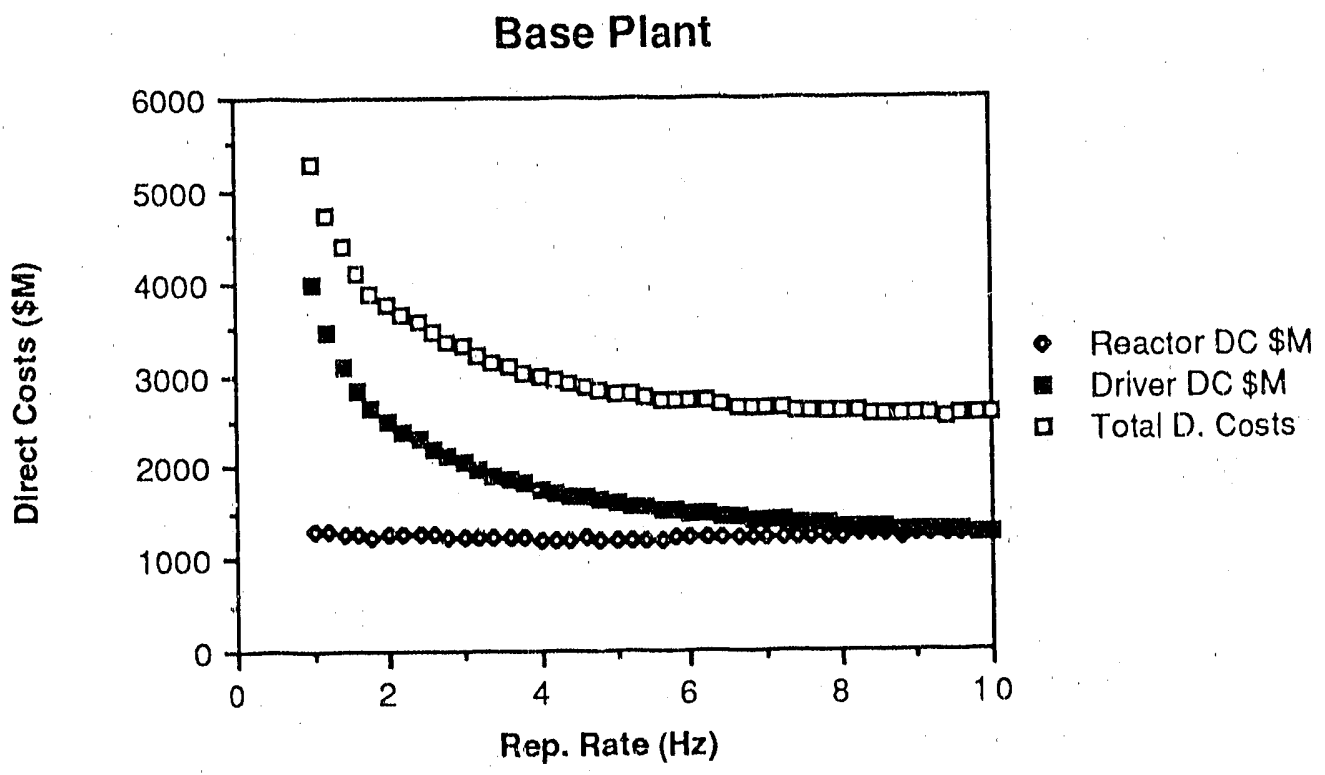

1.9 .11 
Base Plant

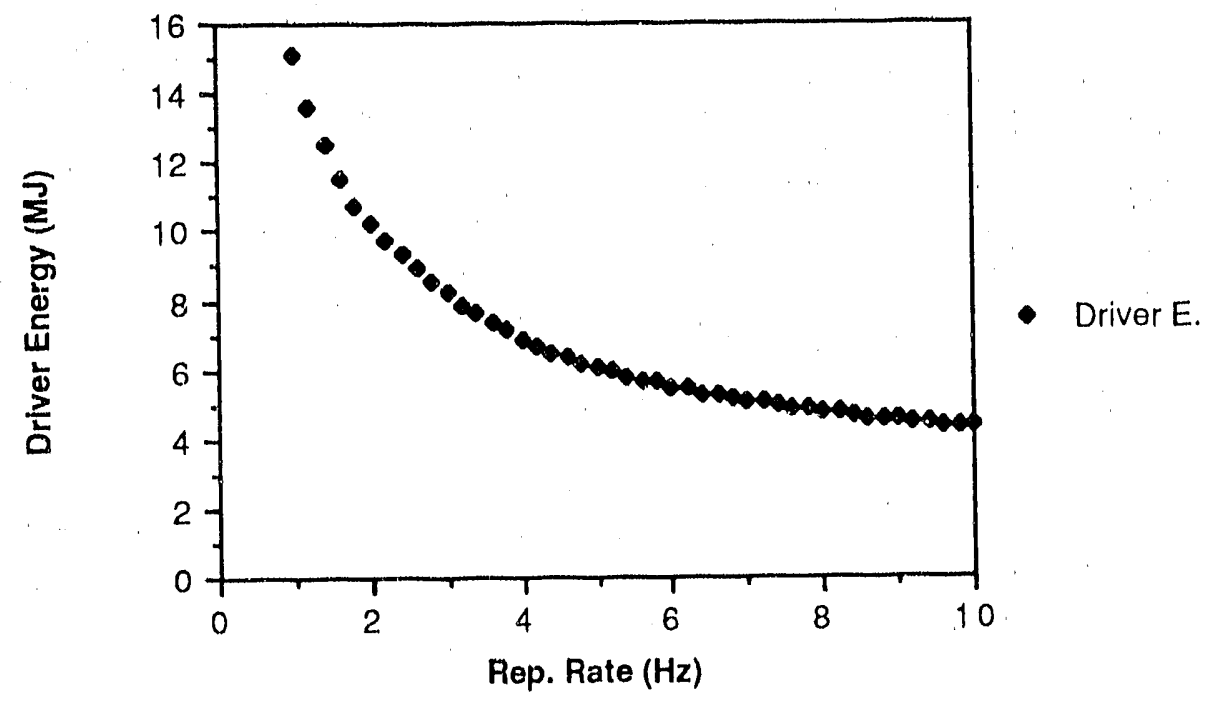

F.1 10 


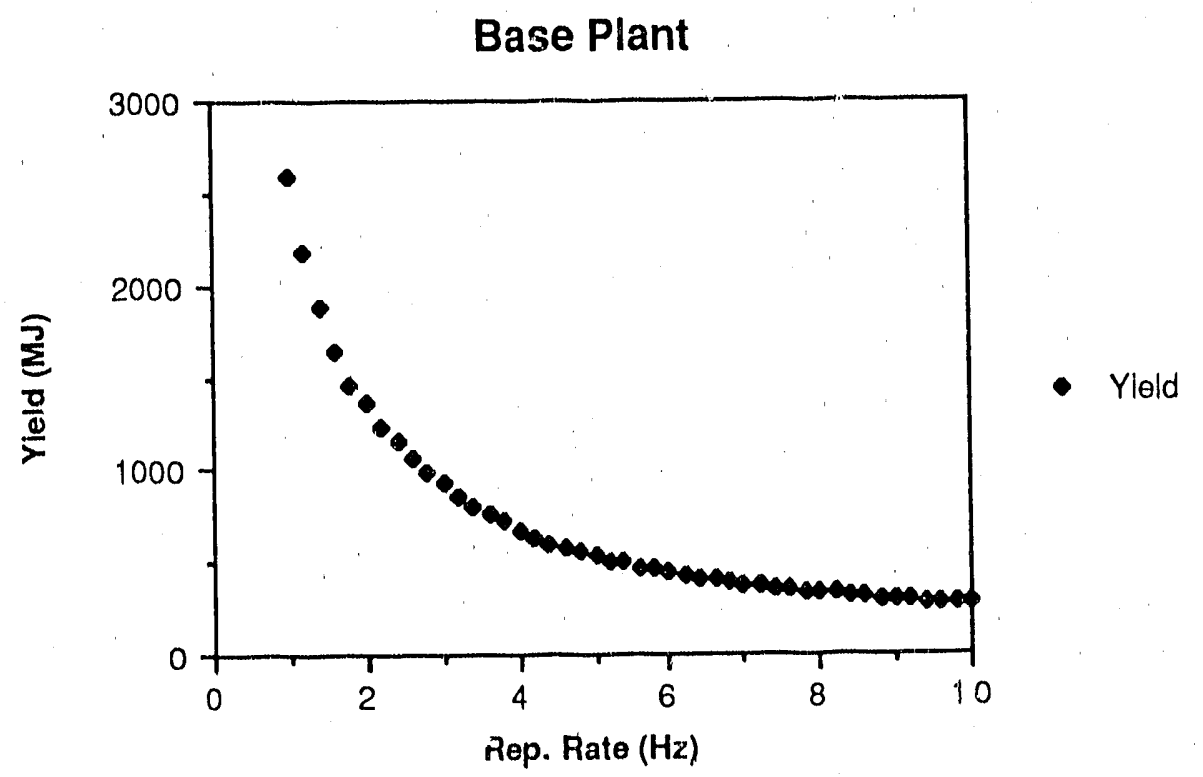

Fig. I d 


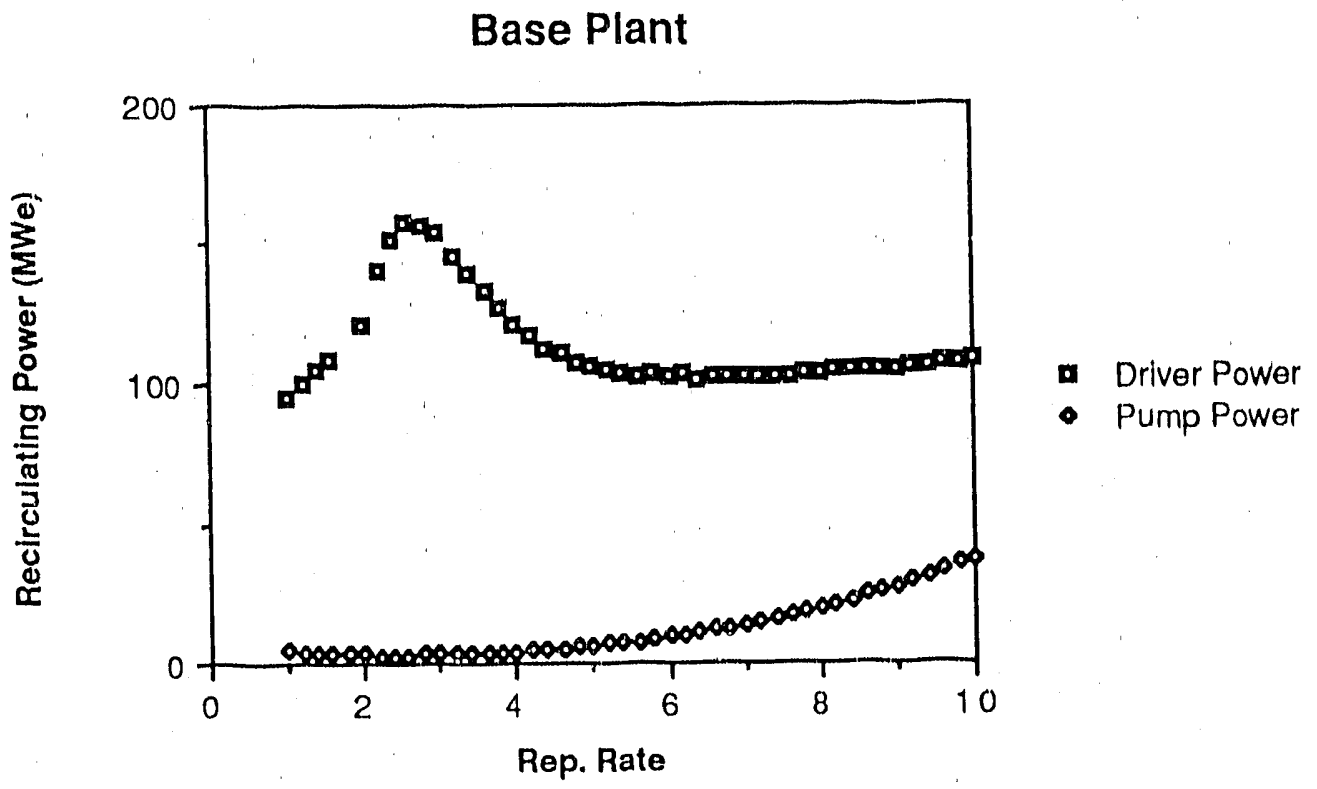

Fig 10 


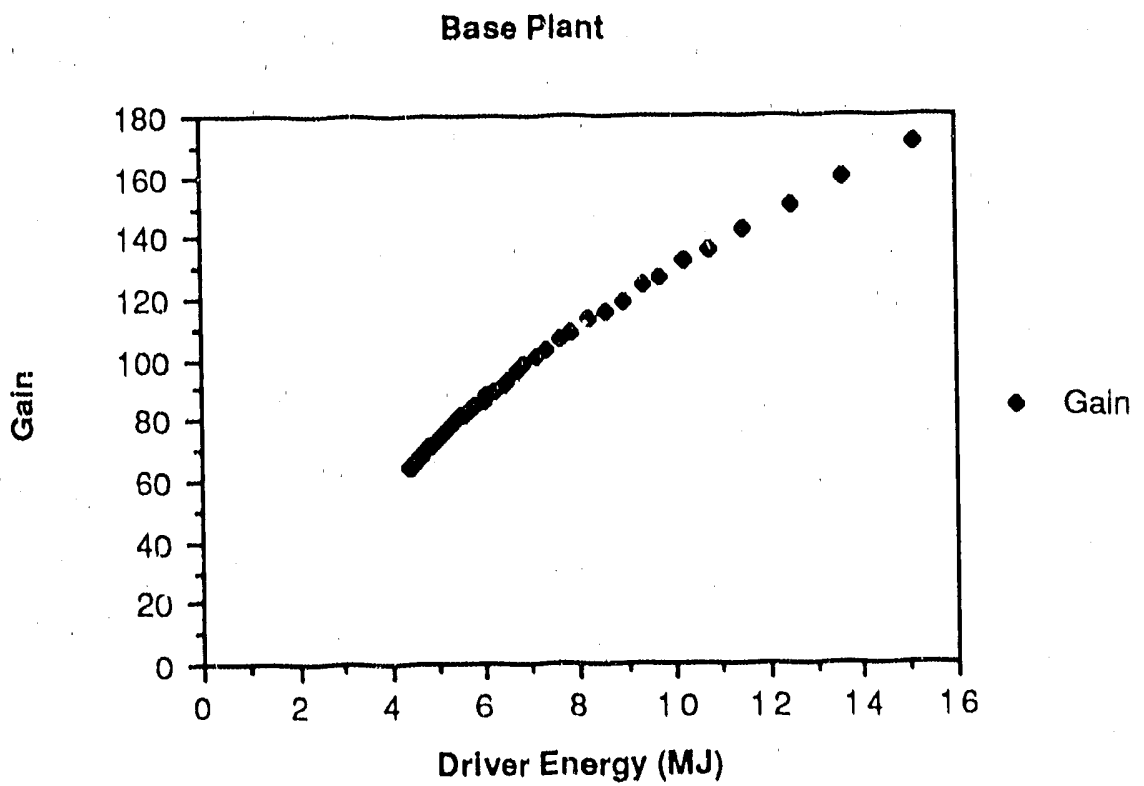



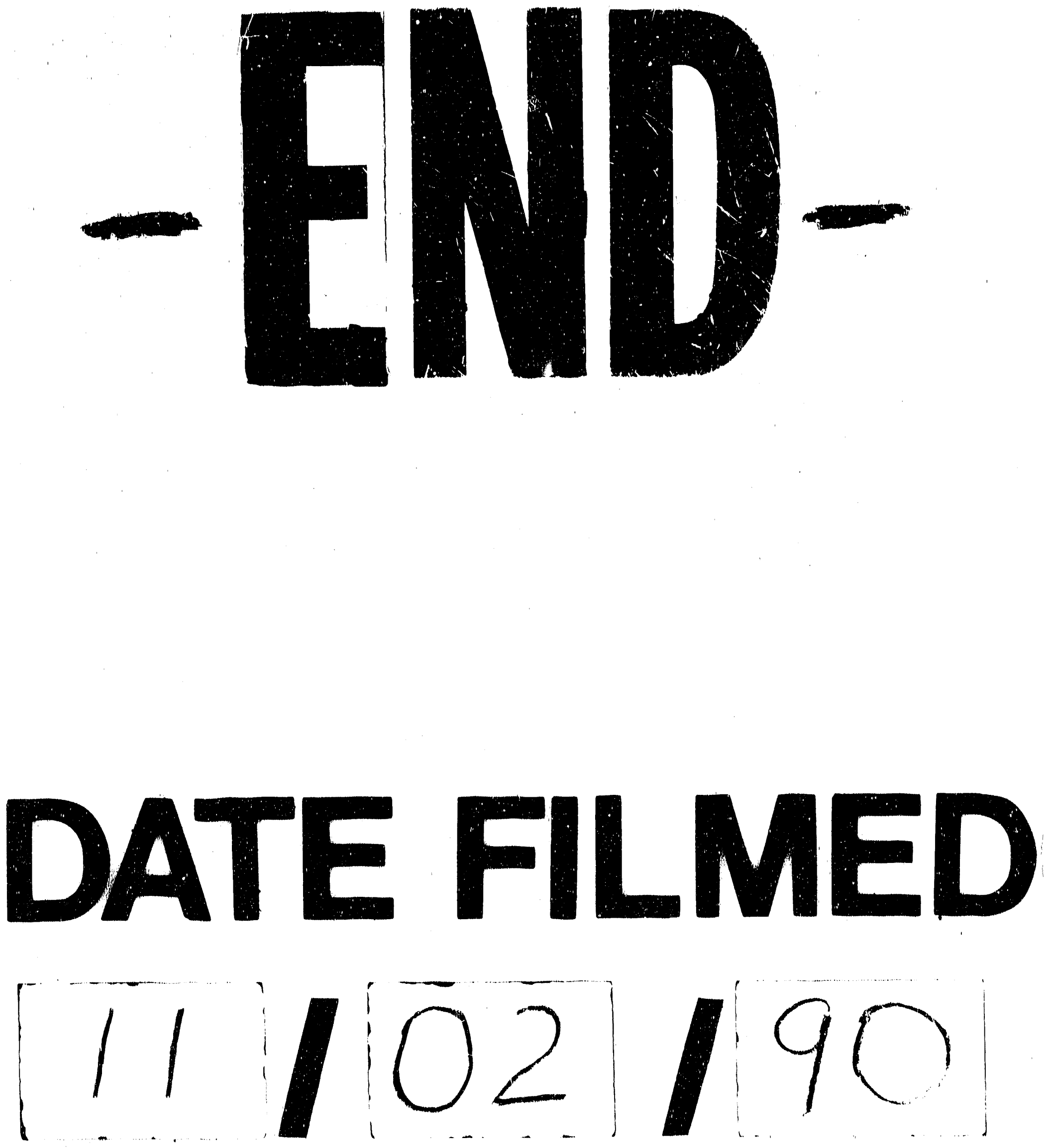
